
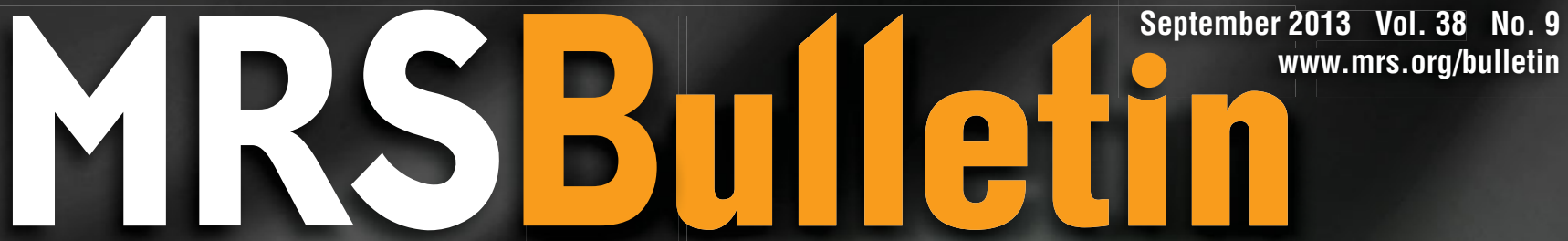

MATERIALS RESEARCH SOCIETY

Advancing materials. Improving the quality of life.

\title{
Quantum dot light-emitting devices
}
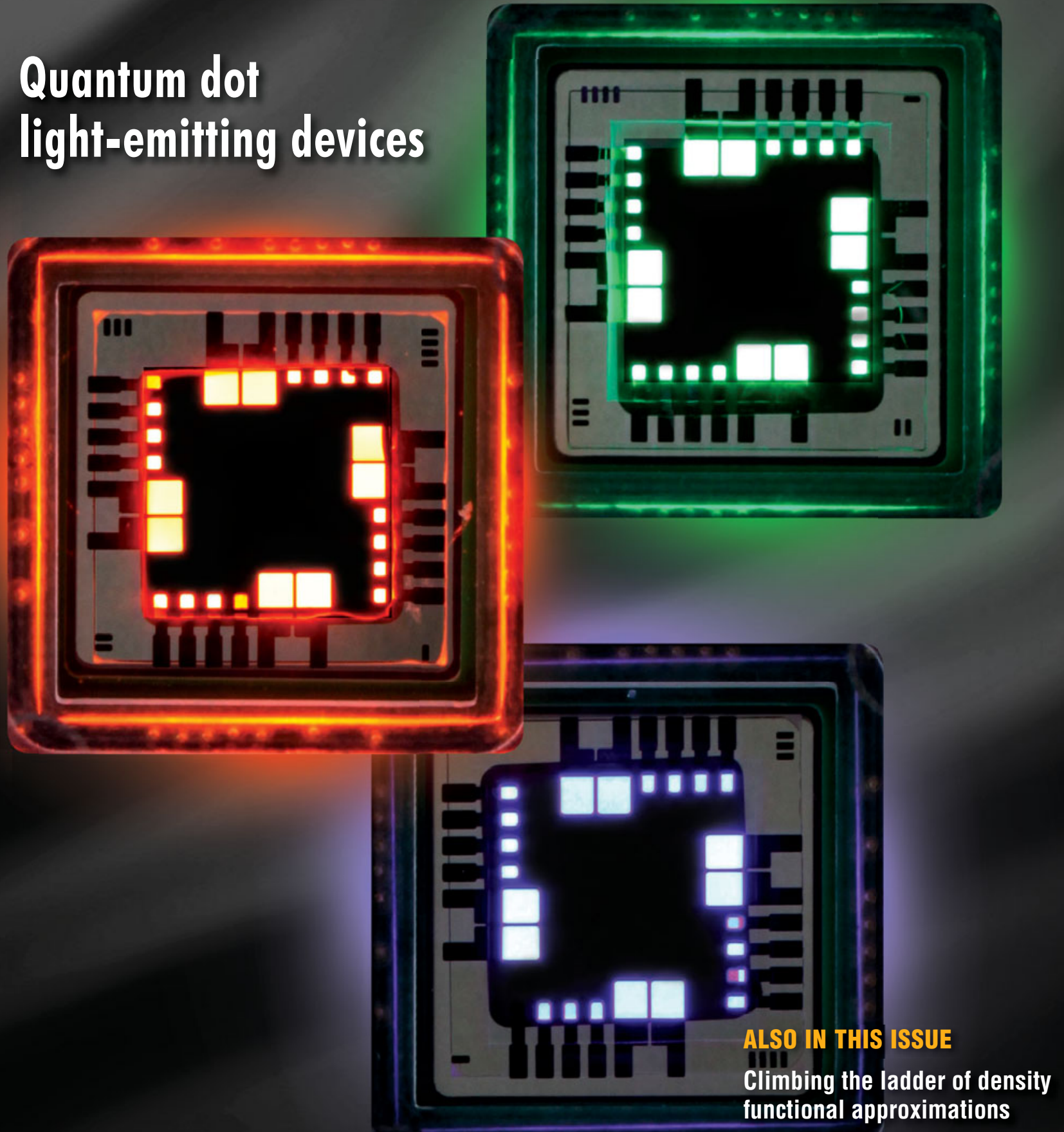


\section{CUSTOMIZED PRODUCTION ION IMPLANTERS}

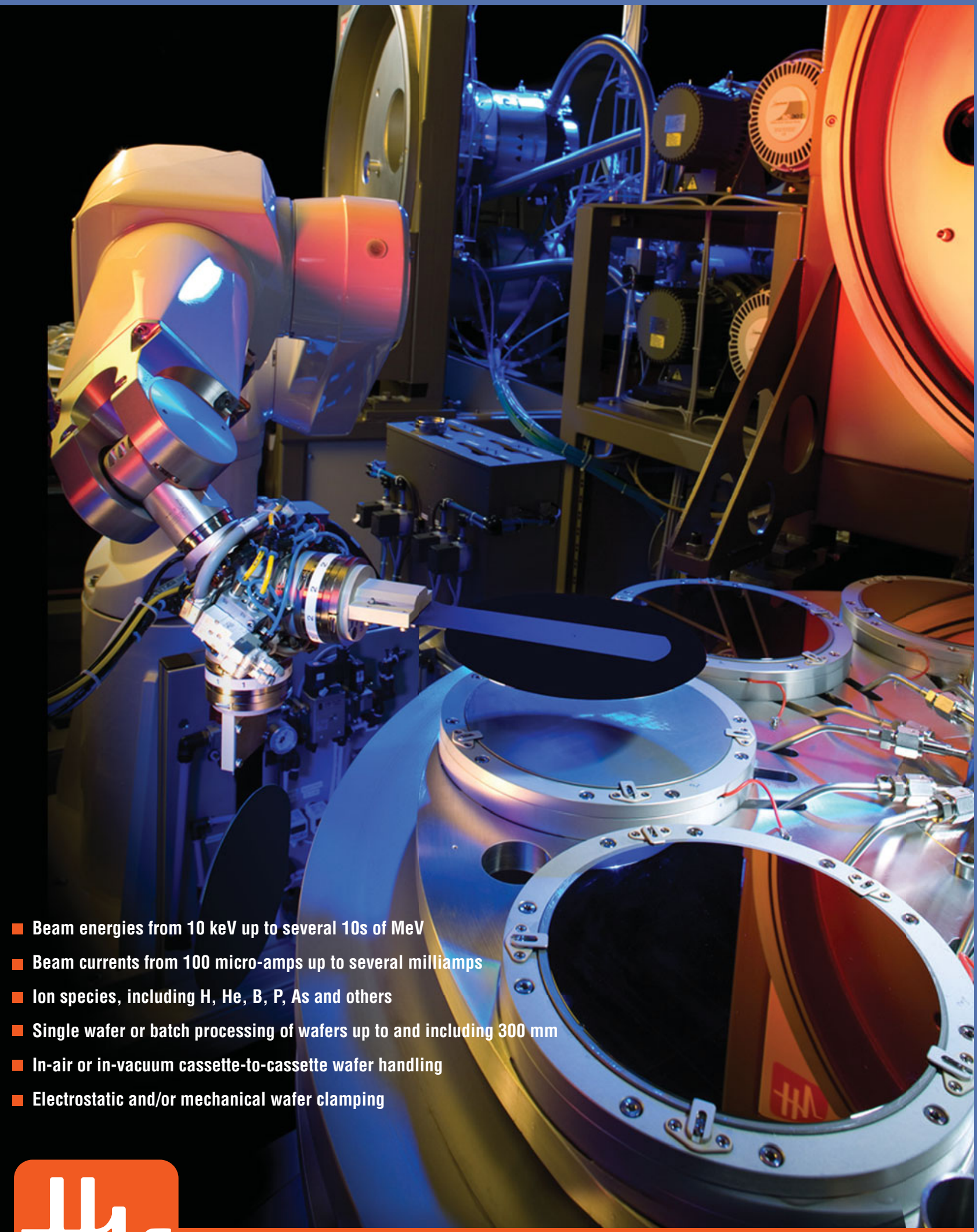

In-air or in-vacuum cassette-to-cassette wafer handling

Electrostatic and/or mechanical wafer clamping

\section{High Voltage Engineering}

High Voltage Engineering Europa B.V.

P.O. Box 99, 3800 AB Amersfoort, The Netherlands

Tel: 31334619741 • info@highvolteng.com

www.highvolteng.com 


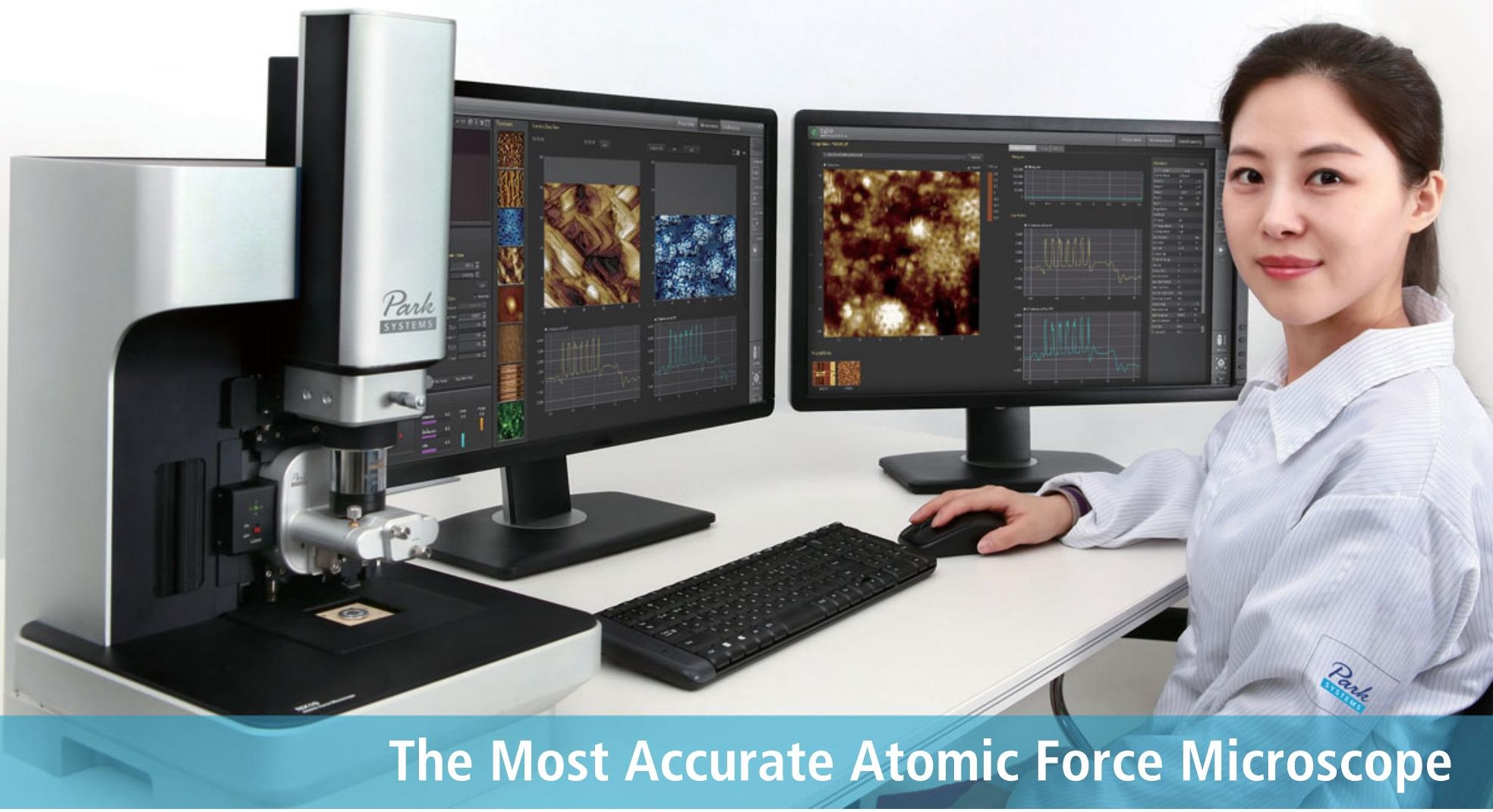

\section{Park NX10 the quickest path to innovative research}

\section{Better accuracy means better data}

Park NX10 produces data you can trust, replicate, and publish at the highest nano resolution. It features the world's only true non-contact AFM that prolongs tip life while preserving your sample, and flexure based independent $X Y$ and $Z$ scanner for unparalleled accuracy and resolution.

\section{Better accuracy means better productivity}

From sample setting to full scan imaging, measurement, and analysis,

Park NX10 saves you time every step of the way. The user friendly interface, easy laser alignment, automatic tip approach, and analysis software allow you to get publishable results faster.

\section{Better accuracy means better research}

With more time and better data, you can focus on doing more innovative research. And the Park NX10's wide range of measurement modes and customizable design means it can be easily tailored to the most unique projects.

To learn more about Park NX10 or to schedule a demo please call: +1-408-986-1110 or email inquiry@parkafm.com
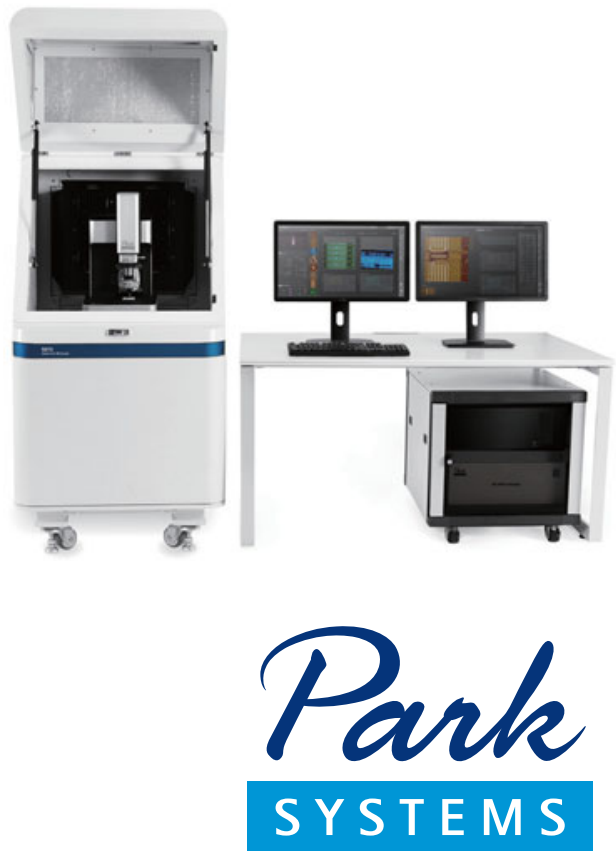


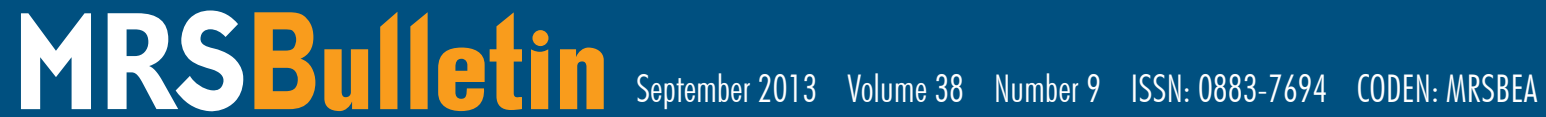
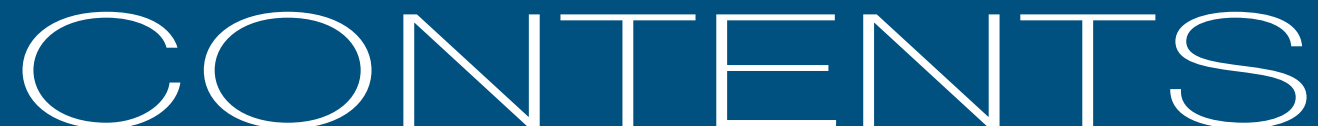

\section{QUANTUM DOT LIGHT-EMITTING DEVICES}

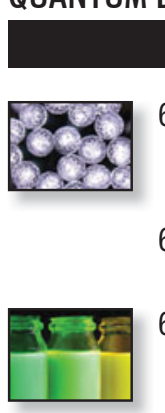

685 Quantum dot light-emitting devices

Dmitri V. Talapin and Jonathan Steckel, Guest Editors

\section{Meet Our Authors}

696 Pure colors from core-shell quantum dots Ou Chen, He Wei, Axel Maurice, Moungi Bawendi, and Peter Reiss

703 QLEDs for displays and solid-state lighting Geoffrey J. Supran, Yasuhiro Shirasaki, Katherine W. Song, Jean-Michel Caruge, Peter T. Kazlas, Seth Coe-Sullivan, Trisha L. Andrew, Moungi G. Bawendi, and Vladimir Bulović

712 Bright and stable quantum dots and their applications in full-color displays Tae-Ho Kim, Shinae Jun, Kyung-Sang Cho, Byoung Lyong Choi, and Eunjoo Jang

721 Spectroscopic insights into the performance of quantum dot light-emitting diodes Wan Ki Bae, Sergio Brovelli, and Victor I. Klimov

731 Challenges and solutions for high-efficiency quantum dot-based LEDs

Deniz Bozyigit and Vanessa Wood

737 Beyond quantum dot LEDs: Optical gain and laser action in red, green, and blue colors Cuong Dang and Arto Nurmikko

\section{TECHNICAL FEATURE}

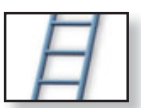

743 Climbing the ladder of density functional approximations

2012 MRS Materials Theory Award

John P. Perdew

\section{Energy Quarterly}

677 Editorial

With steel, cement, and mortar

V.S. Arunachalam

678 Energy Sector Analysis

A concrete path to sustainability

Prachi Patel

FEATURE EDITOR: José Fernando Martirena

Hernández

680 Energy Sector Analysis

A test of the steel industry's metal

Prachi Patel

FEATURE EDITOR: Sridhar Seetharaman

682 Interview

Dresselhaus recounts work on energy-related materials

Interviewed by Steve Yalisove

www.mrs.org/energy-quarterly

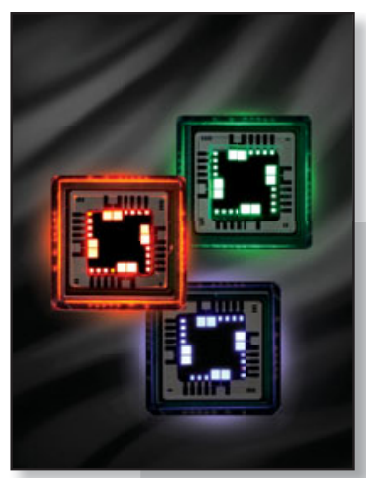

ON THE COVER

Quantum dot light-emitting devices. This issue of MRS Bulletin covers the application of colloidal quantum dots for use in lighting technologies. Quantum dot lightemitting diodes (QLEDs) represent a technical challenge as well as majo commercial opportunity for display and solid-state lighting applications. Recent developments show that efficiency and brightness of QLEDs can match those of organic LEDs. The cover shows images of red, green, and blue QLEDs. See the technical theme that begins on page 685 . 


\section{DEPARTMENTS}

\section{- NEWS \& ANALYSIS}

670 Materials News

- Single atoms imaged in situ with environmental STEM

Emily Lewis

- Crystalline reflectors enable ultralow-thermal-noise optical cavities Colin McCormick

- Hard talk to stem cells for new bone growth Lukmaan A. Bawazer

- $\mathrm{LuMnO}_{3}$ thin films reveal ferromagnetic and antiferromagnetic properties simultaneously

- Li-ion microbattery fabricated by 3D printing

673 Science Policy

- Universities prepare next-generation workforce to benefit from the Materials Genome Initiative Ashley A. White

- EU and industry join forces to invest €22 billion in research and innovation

\section{FeATURES}

675 Beyond the Lab

Bruce Clemens teaches materials science online Interviewed by Piper Klemm

759 Posterminaries

Toying with science

Robin Selinger

\section{SOCIETY NEWS}

- Survey on Big Data gathers input from materials community

Lori A. Wilson

\section{CAREER CENTRAL}

ADVERTISERS IN THIS ISSUE

Aldrich Materials Science

American Elements

American Scientific Publishers

Angstrom Engineering, Inc.

CRAIC Technologies, Inc.

High Voltage Engineering

Hindawi Publishing Corporation

Janis Research Company, LLC

MMR Technologies, Inc.

National Electrostatics Corp

Park Systems, Inc.

Rigaku Corporation

Strem Chemicals, Inc.

ULVAC Technologies, Inc.

\section{Page No.}

.684 . Outside back cover

669

...Inside front cover Inside back cover

750

702

695

www.mrs.org/bulletin

MRS members-access MRS Bulletin online

www.mrs.org/energy-quarterly

Access Energy Quarterly online

www.mrs.org/mymrs

MRS Publications Alert-

receive advance Table of Contents by email

http://journals.cambridge.org/

mrsbulletin-rss

Subscribe TODAY to the MRS Bulletin RSS Feed

Design images used under license from Shutterstock.com 


\section{About the Materials Research Society}

The Materials Research Society (MRS), a not-for-profit scientific association founded in 1973 and headquartered in Warrendale, Pennsylvania, USA, promotes interdisciplinary materials research. Today, MRS is a growing, vibrant, member-driven organization of over 16,000 materials researchers spanning over 80 countries, from academia, industry, and government, and a recognized leader in the advancement of interdisciplinary materials research.

The Society's interdisciplinary approach differs from that of single-discipline professional societies because it promotes information exchange across many scientific and technical fields touching materials development. MRS conducts three major international annual meetings encompassing approximately 125 topical symposia, and also sponsors numerous single-topic scientific meetings. The Society recognizes professional and technical excellence and fosters technical interaction through University Chapters. In the international arena, MRS implements bilateral projects with partner organizations to benefit the worldwide materials community. The MRS Foundation helps the Society advance its mission by supporting various projects and initiatives.

MRS publishes MRS Bulletin, MRS Communications, the MRS Online Proceedings Library, Journal of Materials Research, MRS Energy \& Sustainability, and books and textbooks with its publishing partner, Cambridge University Press.

2013 MRS BOARD OF DIRECTORS

President Orlando Auciello, University of Texas at Dallas, USA

Immediate Past President Bruce M. Clemens, Stanford University, USA

Vice President and President-Elect Tia Benson Tolle, The Boeing

Company, USA

Secretary Sean J. Hearne, Sandia National Laboratories, USA

Treasurer Michael R. Fitzsimmons, Los Alamos National Laboratory, USA

Executive Director Todd M. Osman, Materials Research Society, USA

Ana Claudia Arias, University of California-Berkeley, USA

Shenda Baker, Synedgen, Inc/Harvey Mudd College, USA

David Cahen, Weizmann Institute of Science, Israel

Duane B. Dimos, Sandia National Laboratories, USA

Steve Eglash, Stanford University, USA

Chang-Beom Eom, University of Wisconsin-Madison, USA

Susan Ermer, Lockheed Martin Advanced Technology Center, USA

Eric Garfunkel, Rutgers University, USA

Sossina M. Haile, California Institute of Technology, USA

Andrea M. Hodge, University of Southern California, USA

Oliver Kraft, Karlsruhe Institute of Technology, Germany

Hideki Matsumura, Japan Advanced Institute of Science and Technology, Japan

Fiona C. Meldrum, University of Leeds, UK

Eric A. Stach, Brookhaven National Laboratory, USA

Stephen Streiffer, Argonne National Laboratory, USA

Susan E. Trolier-McKinstry, The Pennsylvania State University, USA

\section{MRS OPERATING COMMITTEE CHAIRS}

Academic Affairs M. Stanley Whittingham, SUNY-Binghamton, USA

Awards C. Barry Carter, University of Connecticut, USA

Government Affairs Nabil Bassim, US Naval Research Laboratory, USA

Meetings Committee David S. Ginley, National Renewable Energy

Laboratory, USA

Member Engagement Yves Chabal, The University of Texas at Dallas, USA Public Outreach Aditi Risbud, University of Utah in Salt Lake City, USA

Publications Paul McIntyre, Stanford University, USA

MRS OFFICE OF PUBLIC AFFAIRS

Ron Kelley 499 South Capitol St. SW, Suite 600, Washington, DC 20003
EDITORIAL OFFICE 506 Keystone Drive, Warrendale, PA 15086-7573 USA Bulletin@mrs.org tel 724.779.2747 fax 724.779.8313 www.mrs.org
Editor

Gopal R. Rao, rao@mrs.org

Managing Editor

Judy Meiksin, meiksin@mrs.org

Technical Editor

Lori A. Wilson, Iwilson@mrs.org

Editorial Assistants

Graeme Lister

Ben Moriarty, moriarty@mrs.org

Mary Wilmoth

Associate Technical Editor

B. Reeja Jayan

Production/Design

Andrea Pekelnicky, Rebecca Yokum,

and TNQ

Production Editor

Catherine Paduani

Science News Editor

Tim Palucka

Principal Development Editor

Elizabeth L. Fleischer

Director of Communications

Eileen Kiley Novak
Guest Editors

Dmitri V. Talapin and Jonathan Steckel

Special Consultants

Philip Purnell and Karen Scrivener

Energy Quarterly

David Cahen (Chair),

Anshu Bharadwaj, Russell R. Chianelli,

George Crabtree, Sabrina Sartori,

Anke Weidenkaff,

M. Stanley Whittingham,

and Steve M. Yalisove

Advertising/Sponsorship

Mary E. Kaufold, kaufold@mrs.org

Donna L. Watterson, watterson@mrs.org

Member Subscriptions

Michelle Judt, judt@mrs.org

Non-Member Subscriptions

subscriptions_newyork@cambridge.org

\section{EDITORIAL BOARD}

Paul S. Drzaic (Chair), Apple, Inc., USA

V.S. Arunachalam, Center for Study of Science, Technology \& Policy, India

Marie-Isabelle Baraton, University of Limoges, France

Hanns-Ulrich Habermeier, Max Planck Institute for Solid State Research, Germany

Igor Lubomirsky, Weizmann Institute, Israel

Fiona C. Meldrum, University of Leeds, UK

Amit Misra, Los Alamos National Laboratory, USA

Steven C. Moss, Aerospace Corporation, USA

Julie A. Nucci, Cornell University, USA

Linda J. Olafsen, Baylor University, USA

Carol Trager-Cowan, University of Strathclyde, UK

Eric Werwa, Washington, DC, USA

Steve M. Yalisove, University of Michigan, USA

\section{VOLUME ORGANIZERS}

2014 Deborah E. Leckband, University of Illinois at Urbana-Champaign, USA Yuri Suzuki, Stanford University, USA

Enrico Traversa, King Abdullah University of Science and Technology, Saudi Arabia Yonhua Tzeng, National Cheng Kung University, Taiwan

2013 Mark T. Lusk, Colorado School of Mines, USA Eva Olsson, Chalmers University of Technology, Sweden Birgit Schwenzer, Pacific Northwest National Laboratory, USA James W. Stasiak, Hewlett-Packard Co., USA

2012 Lei Jiang, Chinese Academy of Sciences, China Sergei V. Kalinin, Oak Ridge National Laboratory, USA Stéphanie P. Lacour, EPFL, Switzerland Steven C. Moss, Aerospace Corporation, USA Materials Research Society. Permission required to reproduce content. Periodical postage paid at New York, NY, and at additional mailing offices. POSTMASTER: Send address changes to MRS Bulletin in care of the Journals Department, Cambridge University Press, 100 Brook Hill Drive, West Nyack, NY 10994-2113, USA. Printed in the U.S.A.

Membership in MRS is $\$ 115$ annually for regular members, $\$ 30$ for students. Dues include an allocation of $\$ 29$ ( $\$ 17$ for students) to a subscription to MRS Bulletin. Individual member subscriptions are for personal use only. Non-member subscription rates are $\$ 394$ for one calendar year (12 issues) within North America and $\$ 479$ elsewhere. Requests from subscribers for missing journal issues will be honored without charge only if received within six months of the issue's actual date of publication.

(1) base, Research Alert ${ }^{\oplus}$ Science Citation Index ${ }^{\circledast}$, and the Materials Science Citation IndexTM. Back volumes of MRS Bulletin are available on microfiche through University Microfilms Inc. 300 North Zeeb Road, Ann Arbor, MI 48106, USA. 


\section{NANOSGIENGE AND NANOTECHNOLOGY}

25-Volume Set

\section{KEY FEATURES}

- The 25 volume set is a landmark reference that contains the largest number of research articles in the world

- Most up-to-date reference work ever published drawing on the past two decades of pioneering research

- 710 review chapters (ca. 20,000 pages) contributed by nearly 2,000 of the world's leading scientists

- All entries organized alphabetically in an $\mathbf{A - Z}$ order, browsing capabilties within different categories

- Edited and written by internationally known authoritative experts familiar with current technologies

- Truly international: authors from $\mathbf{4 0}$ countries

- Approximately 150,000 bibliographic citations providing extensive cross-referencing in each article

- About 15,000 figures, 1,400 tables and hundreds of chemical structures and equations

- Timely, authoritative and most comprehensive

- Extensive cross-referencing in each article provides reader with broader range of knowledge

- Available Online Edition allowing multiple users and fully searchable text

- Essential source for students, scientists, college and university professors, professionals, investors

(1)

0

(1)

(1)

(1)

(1)

Q

$\frac{1}{3}$

- Multidisciplinary reference source for researchers spanning from science to engineering to medicine

Editor

Dr. Hari Singh Nalwa, USA

Editor-in-Chief

Journal of Nanoscience

and Nanotechnology

www.aspbs.com/jnn

\section{www.asplbs.com/enn}

The first edition of the Encyclopedia of Nanoscience and Nanotechnology, 10-Volume Set, (Foreword by Professor Richard E. Smalley, Nobel Prize Laureate, Endorsed by Professor Jean-Marie Lehn, Nobel Prize Laureate) that appeared in 2004 received the "Best Reference Work Award" of the American Society for Engineering Education and "Outstanding Academic Title" by the CHOICE magazine from the American Library Association.

With the addition of new 15 volumes (vols. 11-25) in 2011, the entire 25-volume set contains the largest number of articles ever published in the field of nanotechnology in the world. It is the most useful reference for all academic and research libraries.

- Volume 1-10, ISBN: 1-58883-001-2 (2004)

- Volume 11-25, ISBN: 1-58883-159-0 (2011)

$\sqrt{25 \%}$ Loyalty Discount on 15-volume set to customers who own volumes $1-10$ set!

Available in Print \& Online Editions
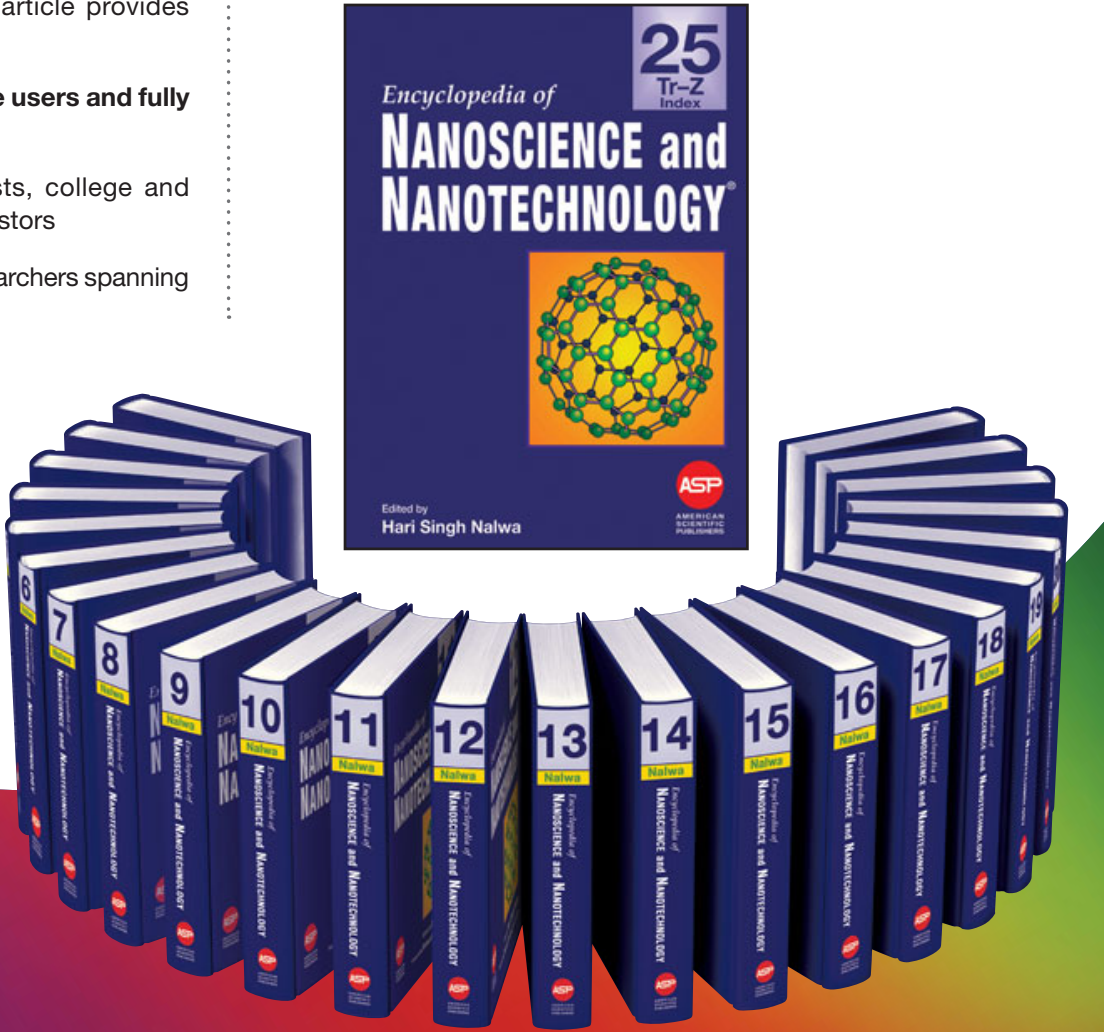

American Scientific Publishers 26650 The Old Road, Suite 208 Valencia, California 91381, USA

Tel. 661-799-7200 Fax:661-799-7230 order@aspbs.com www.aspbs.com 